\title{
Embracing complexity
}

Rebecca Wassall, Clinical Lecturer in Special Care Dentistry,

School of Dental Sciences, Newcastle University, Newcastle, UK

The BDJ Upfront section includes editorials, letters, news, book reviews and interviews. Please direct your correspondence to the News Editor,

Kate Quinlan at k.quinlan@nature.com. Press releases or articles may be edited, and should include a colour photograph if possible.

$\mathrm{I}$ $\mathrm{t}$ is a real honour to introduce, as guest editor, this $B D J$ special care dentistry themed issue. The complexity found in special care dentistry brings with it tensions and paradoxes. It requires practitioners to engage with creative, reflexive and collaborative ways of working and thinking. Practising in this way is essential for the safety and quality of care but takes time and obviously requires specific capability. How we cope with and even embrace complexity in special care dentistry is the golden thread that runs through this issue and I am extremely grateful to my colleagues who have written contributions. I feel sure that, whatever your connection to special care dentistry, you will find something of interest in this issue.

The multi-morbidity and interacting sociocultural influences, so often present in the practice of special care dentistry, bring into sharp focus the challenges of dealing with the mismatch between the 'patient in the guideline' and the 'patient in the dental chair'.

It is temptingly easy to think of dentistry as if it were a drug or dental material. Doing so makes life so much easier for everyone. It allows dentists to plan their work with a high degree of certainty, commissioners to be confident that they know what they are buying and researchers to focus on testing whether or not 'it' is working. But of course most dentists know that special care dentistry is not as simple as that.

Often, the planned care (eg management of a painful and grossly carious upper right molar tooth) and the context (eg patient is a frail 80-year-old man with a persistent dry mouth, who is taking multiple medications including bisphosphonates and anticoagulants, lives at home in a deprived rural community with limited public transport links and caring for his wife of 60 years who is living with dementia) will have multiple strands that are inter-related. In a situation such as this there can be a gap between the evidence-based ideal and the realities of the here and now. How we individualise evidence and support shared decisions through meaningful conversations in the context of a person-centred and professional clinician-patient relationship is at the heart of special care dentistry.

As part of an inclusive society it is vital that we enable some aspects of special care dentistry to happen consistently across primary dental care. In addition, we must ensure that patients with more complex needs can get care from a specialist in special care dentistry, whilst accepting the line at which a referral should be made is often blurred.

Unfortunately, the whole health and care system currently isn't that well geared up to experienced within special care dentistry.

Hurst argues that we should be transparent about the paradoxes, meaning and values inherent in the practice of dentistry and he suggests the use of stories and narratives are important if we really want to evaluate and improve practices.

Brocklehurst et al. explore how involving non-researchers (patients, professionals, policy makers) in research within the field of special care dentistry can result in relevant research, contextually sensitive interventions and meaningful measures for evaluation.

Scambler and Curtis contextualise the relationship between disability and dentistry within the wider debates about material, social

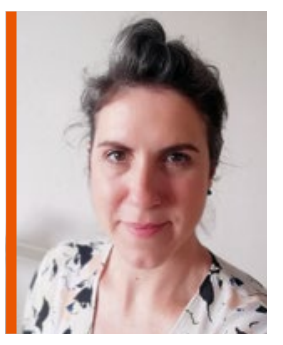

\section{'As part of an inclusive society it is vital} that we enable some aspects of special care dentistry to happen consistently across primary dental care'

ensure dental care is available for patients with complex needs. So we currently have a choice. We either accept this situation or we work to change it. Commissioning of dental services, education of our workforce and knowledge sharing as part of clinical care will need to develop to ensure resources and capability are available to support safe and effective care.

This themed issue covers pieces on broad topics important to special care dentistry including understanding and tackling oral health inequalities, exploring complexity and evidence-based practice, promoting co-production in research and service improvement, preparing the new dental graduate in this field; and challenging perceptions of disability as we work to remove barriers to oral health.

Watt et al. present recommended actions to improve access to dental services and policies to combat oral health inequalities and cultural barriers that disabled people face.

This themed issue also includes pieces that focus on more specific clinical areas relevant to special care dentistry including a literature review of the provision of dental treatment for people with drug dependency, a qualitative research study exploring patients' and dentists' experiences of bariatric dental care and three clinical case reports.

The safe and high quality practice of special care dentistry is dependent on our ability to cope with complexity. This includes how we educate the dental team for capability not simply competence, support meaningful discussions on how to interpret and apply evidence in real cases, and importantly how we share collective knowledge and expertise among dental care professionals. I hope you enjoy the issue!

DOI:10.1038/s41415-019-0520-3 